\title{
Comparison of cannulated lag screws and lateral locking plate in the treatment of Schatzker type II tibial plateau fractures
}

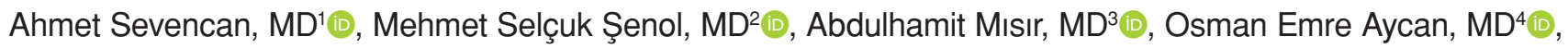 \\ Akif Albayrak, MD5ㅁ, Hanifi Uçpunar, $\mathrm{MD}^{6}{ }^{\mathbb{D}}$ \\ ${ }^{1}$ Department of Orthopedics and Traumatology, Recep Tayyip Erdoğan University Training and Research Hospital, Rize, Turkey \\ 2Department of Orthopedics and Traumatology, Şanlıurfa Training and Research Hospital, Şanlıurfa, Turkey \\ ${ }^{3}$ Department of Orthopedics and Traumatology, Gaziosmanpaşa Taksim Training and Research Hospital, Istanbul, Turkey \\ ${ }^{4}$ Department of Orthopedics and Traumatology, Acıbadem Maslak Hospital, Istanbul, Turkey \\ ${ }^{5}$ Department of Orthopedics and Traumatology, Baltalimani Bone and Joint Diseases Training and Research Hospital, Istanbul, Turkey \\ ${ }^{6}$ Department of Orthopedics and Traumatology, Erzincan University Mengücek Gazi Training and Research Hospital, Erzincan, Turkey
}

Schatzker type II fractures, defined as the depression of the joint surface accompanied by separation, are the most common type of tibial plateau fractures..$^{[1]}$ These fractures can be treated conservatively or surgically using many methods. Articular step-off $>3 \mathrm{~mm}$, condylar widening $>5 \mathrm{~mm}$ or varus/valgus instability are the main surgical indications for Schatzker type II fractures. ${ }^{[2]}$

The main goals of surgical treatment are anatomic reduction of the joint surface, fixation of the fracture with absolute stability, and allowing early rehabilitation. For these purposes, lag screws, lateral locking or unlocking plates and external fixators can be used. ${ }^{[3]}$ In order to preserve the surrounding soft tissue, which plays an important role in knee joint stabilization and coverage, minimal invasive techniques have become popular. In most cases,

Received: May 02, 2019

Accepted: October 03, 2019

Published online: March 02, 2020

Correspondence: Mehmet Selçuk Şenol, MD. Şanlıurfa Eğitim ve Araştırma Hastanesi Ortopedi ve Travmatoloji Kliniği, 63250 Eyyübiye, Şanlıurfa, Türkiye.

E-mail: selcuksenol@gmail.com

Doi: $10.5606 /$ ehc. 2020.66654

Citation: Sevencan A, Senol MS, Mısır A, Aycan OE, Albayrak A Uçpunar $H$. Comparison of cannulated lag screws and lateral locking plate in the treatment of Schatzker type II tibial plateau fractures. Jt Dis Relat Surg 2020;31(1):130-136.

\section{ABSTRACT}

Objectives: This study aims to compare the clinical and radiological outcomes of the two fixation methods frequently used in the treatment of Schatzker type II fractures: lag screw fixation and lateral anatomic plate fixation.

Patients and methods: This retrospective study, which was conducted between January 2005 and December 2014, included 61 patients (41 males, 20 females; mean age $43.4 \pm 13.1$ years; range, 20 to 76 years) with Schatzker type II (Orthopaedic Trauma Association (OTA)/Arbeitsgemeinschaft für Osteosynthesefragen (AO) 41-B3) fractures. Patients were divided into two groups according to the type of surgery as cannulated lag screw fixation group (group 1, $\mathrm{n}=24,39.4 \%$ ) and lateral locking plate fixation group (group 2, $\mathrm{n}=37,60.6 \%$ ). Intraoperative mediolateral and anteroposterior instability were measured. Final knee flexionextention range of motion (ROM), single-leg hop test, Knee Society Score (KSS), Hospital for Special Surgery (HSS) and short form 36 (SF36) scores were obtained at the last follow-up.

Results: The mean age of patients was $42.1 \pm 13.8$ years in group 2 and $45.5 \pm 12.2$ years in group 1 . The mean follow-up period was $34 \pm 4$ months. Minimal or no arthritis was detected in $75 \%(n=18)$ of patients in group 1 and $78 \%(\mathrm{n}=29)$ of patients in group $2(\mathrm{p}=0.27)$. Single leg-hop test results $(\mathrm{p}=0.55)$, final follow-up knee ROM $(\mathrm{p}=0.40), \operatorname{KSS}(\mathrm{p}=0.21), \operatorname{HSS}(\mathrm{p}=0.15)$, and SF36 scores of group 1 were similar to group 2 . In group 1 , the duration of surgery was shorter $(\mathrm{p}<0.001)$ and the cost of treatment was lower $(\mathrm{p}<0.001)$.

Conclusion: Treatment of Schatzker type II tibial plateau fractures with lag screws seems to provide less invasive, cheaper, and faster surgical treatment as compared with lateral locking plate fixation. In addition, patients who underwent internal fixation with lag screws had similar clinical and radiological outcomes with those who underwent lateral locking plate fixation.

Keywords: Cannulated lag screw, functional outcome, lateral locking plate, open reduction internal fixation, Schatzker type II fractures, tibial plateau fractures. 
depression of the joint surface is apparent. Anatomic reduction and filling the defect with autograft, allograft, cement or bone substitutes are supported. ${ }^{[4]}$

In the literature, there is a lack of consensus about the fixation method of lateral unicondylar tibial plateau fractures. However, lateral locking plate fixation and lag screw fixation are the most widely used surgical methods. While lateral locking plate fixation provides both absolute stability and buttress effect, lag screw fixation is a more costeffective treatment option which could be applied in a minimally invasive way. ${ }^{[5]}$ Therefore, in this study, we aimed to compare the clinical and radiological outcomes of the two fixation methods frequently used in the treatment of Schatzker type II fractures: lag screw fixation and lateral anatomic plate fixation.

\section{PATIENTS AND METHODS}

In this retrospective study, a total of 214 skeletally mature patients with tibial plateau fractures operated in Baltalimani Bone and Joint Diseases Training and Research Hospital between January 2005 and December 2014 were evaluated. Of those, 156 patients' dataincluding pre-and postoperative $\mathrm{X}$-rays, computed tomography (CT) images, and control X-rays for at least one year postoperatively were assessed. Patients were divided as medial, lateral, and bicondylar tibial plateau fracture groups. Seventy-nine patients had lateral tibial plateau fractures with more than $3 \mathrm{~mm}$ joint depression and splitting classified as Schatzker type II fracture (Orthopaedic Trauma Association (OTA)/ Arbeitsgemeinschaft für Osteosynthesefragen (AO) 41-B3). Eight patients with posterolateral corner fracture, three patients with open fractures, and seven patients with grade 3-4 gonarthrosis according to Kellgren and Lawrence osteoarthritis classification system were excluded. ${ }^{[6]}$ Sixty-one patients (41 males, 20 females; mean age 43.4 \pm 13.1 years; range, 20 to 76 years) were enrolled. None of the patients had vascular or neural injury or compartment syndrome in either the pre- or postoperative period. No additional lower extremity fracture was spotted in 53 cases (86.9\%). In eight patients, concurrent fibular head fracture was detected. The study protocol was approved by the Baltalimani Bone and Joint Diseases Training and Research Hospital Ethics Committee (approval number/date: 12/12.09.2014). A written informed consent was obtained from each patient. The study was conducted in accordance with the principles of the Declaration of Helsinki.

Patients were divided into two groups as the cannulated lag screw fixation group (group $1, \mathrm{n}=24$, $39.3 \%, 17$ males, 7 females) and the lateral locking plate fixation group (group 2, n=37, 60.7\%, 24 males, 13 females).

Intraoperative mediolateral and anteroposterior (AP) instability examination and final range of motion (ROM) tests were used in clinical evaluation. At the last follow-up visit, single-leg hop test was performed. Postoperative and final radiographs were evaluated to determine radiological outcomes. Ahlback score was used in the evaluation of the degree of arthritis. ${ }^{[7]}$ Routine postoperative radiological examination schedule was 1, 3, 6, 12, and 24 months and the last follow-up. Knee Society Score (KSS), Hospital for Special Surgery (HSS) and short form 36 (SF-36) scores were obtained at the last follow-up. ${ }^{[8,9]}$

Standard anterolateral approach to the proximal tibia was used in group 2 and mini-incision was used in group 1. The depressed joint surface was elevated from existing fracture line in the anterolateral cortex in both fixation groups. By using submeniscal arthrotomy technique, displaced joint surface was rendered visible. In cases where the anatomic reduction of joint surface was achieved and subchondral bone loss was minimal, the fixation was accomplished by using lateral locking plate (Figure 1) or two or three cannulated lag screws while compressing the fracture line (Figure 2).

Autograft was used in 40 patients. Of these 40 patients, $25(67.5 \%)$ were in group 2 and $15(63 \%)$ were in group 1. All the depressed joint fragments were elevated until restoration of joint surface by graft impactor. After fluoroscopic and direct evaluation of medial and lateral tibial plateau levels and lateral joint surface restoration, internal fixation was performed.

Patients admitted to two orthopedic clinics in our hospital were included in the study. One of these clinics uses only locking plates while the other uses only lag screw fixation to treat Schatzker type II fractures routinely. Thus the type of implant used during the surgery was based on the clinics' choice.

The same postoperative rehabilitation program was applied to all patients. In the postoperative first day, continuous passive motion was started. Passive and active ROM exercises were initiated immediately. Weight bearing was restricted during the first 12 weeks. Then, partial weight bearing with gradual increase was allowed if union was confirmed both clinically and radiologically.

\section{Statistical analysis}

In the descriptive statistics of the obtained data, the values were expressed as mean, standard deviation, median, lowest, highest, rate, and frequency. The 

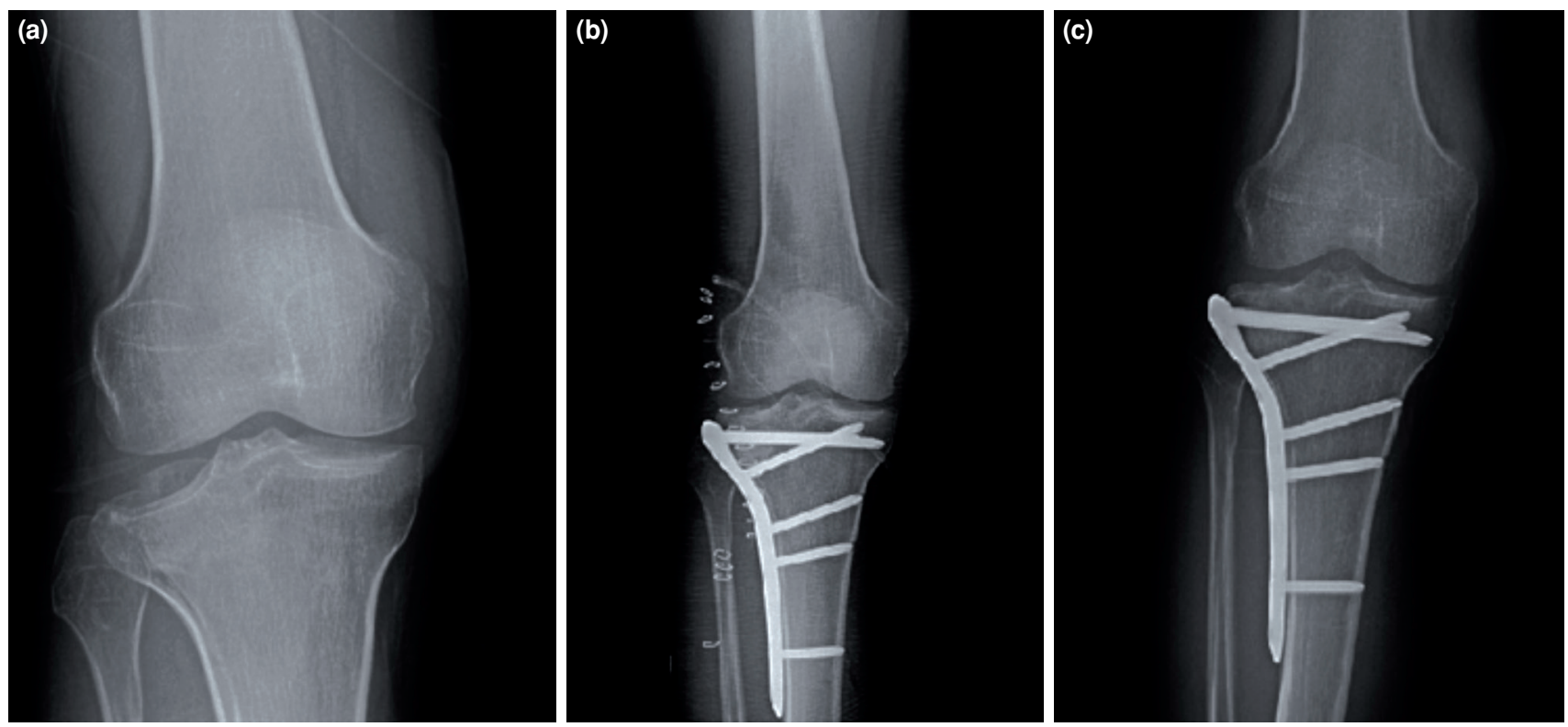

FIGURE 1. (a) Preoperative, (b) early and (c) long-term postoperative radiographs of a patient treated with lateral locking plate.

distribution of variables was controlled by ShapiroWilk test. For the analysis of quantitative data, independent sampling t-test used. For the analysis of qualitative data, chi-square test/Fisher's exact test was performed. IBM SPSS statistics version 19.0 software (IBM Corp., Armonk, NY, USA) was used for statistical analysis.

\section{RESULTS}

Mean follow-up period was $34 \pm 4$ months (range, 13 to 110 months). The mean lateral plateau diastasis in preoperative CT scan was $7.8 \mathrm{~mm}$ (range, 2 to $16 \mathrm{~mm}$ ). The mean lateral plateau depression was $14.6 \mathrm{~mm}$ (range, 6 to $20 \mathrm{~mm}$ ). Postoperative residual (a)

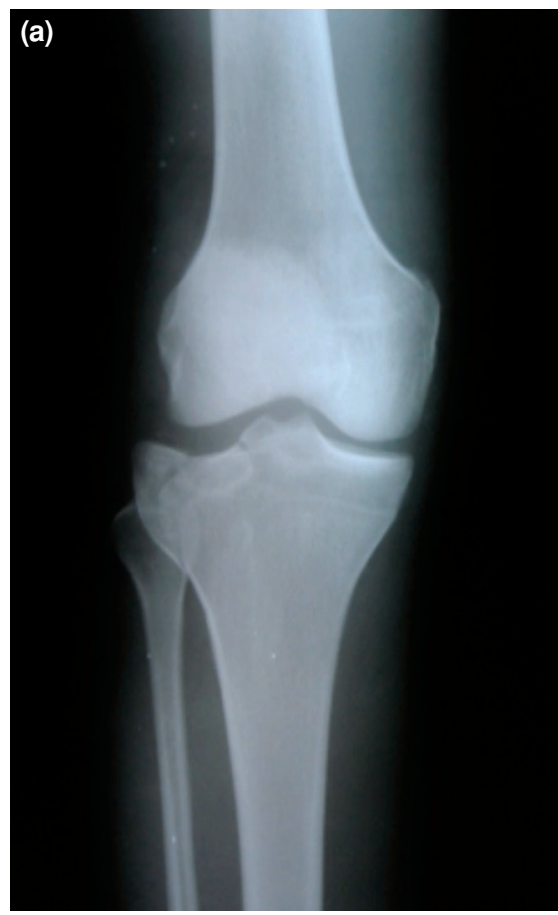

(b)

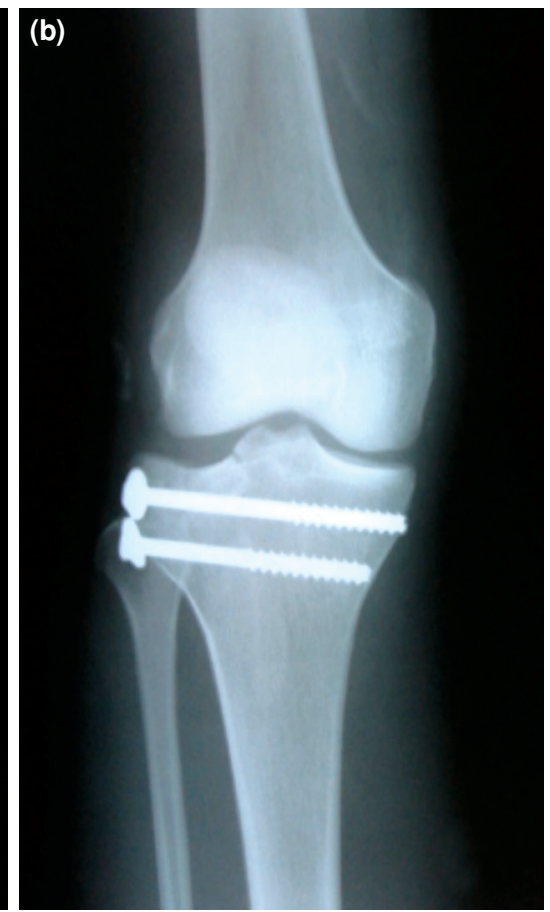

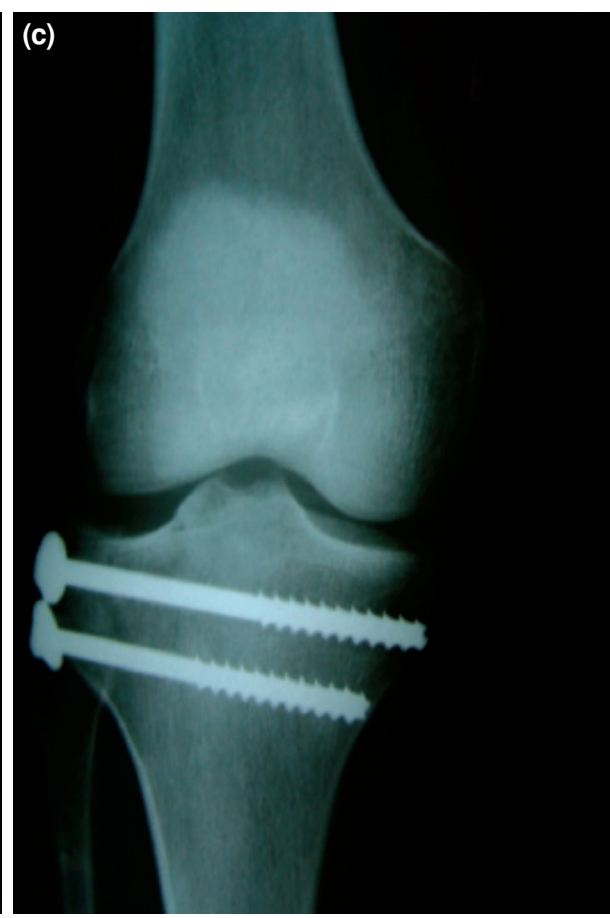

FIGURE 2. (a) Preoperative, (b) early and (c) long-term postoperative radiographs of a patient treated with cannulated lag screws. 
diastasis of $2 \mathrm{~mm}$ was detected in two patients $(3.2 \%)$. The opposite side was used as reference.

The mean duration of surgery was $99.3 \pm 55.3$ minutes (range, 35 to 240 minutes) in group 1, whereas it was $133.1 \pm 56.2$ minutes (range, 52-330 minutes) in group 2 . There was a statistically significant difference between two groups in terms of surgery durations $(\mathrm{p}<0.001)$. Since the patients with longer operation duration had additional injuries that did not meet the exclusion criteria but required simultaneous surgical treatment, and the data were obtained from the hospital's registration system, the duration of surgery in some patients appears to be long.

There was no significant difference between the groups in terms of gender, age, pre- and postoperative arthritis, mediolateral instability, body mass index, and AP instability (Table I).
The mean duration of hospital stay was $3.04 \pm 1.5$ days (range, 1 to 7 days) in group 1, whereas it was $4.05 \pm 1.9$ days (range, 2 to 7 days) in group 2. The difference was statistically significant $(p=0.03)$. When both groups were compared in terms of mean material cost, group 1 had a mean US\$211.6 (range, US\$85.2 to US\$426.4) cost while group 2 had a mean US\$696.7 (range, US\$639.7 to US\$937.8) cost, with a statistically significant difference $(\mathrm{p}<0.001)$ (Table I).

The frequency of mediolateral instability was $37.5 \%$ in group 1 and $48.7 \%$ in group $2(p=0.39)$. The frequency of AP instability evaluated by Lachman test according to the contralateral side was $32.5 \%$ in group 1 and $33.3 \%$ in group $2(p=0.94)$ (Table I).

Single-leg hop test results and the average final ROM in groups 1 and 2 were similar $(p=0.55$ and $\mathrm{p}=0.40$, respectively). There was no significant

\begin{tabular}{|c|c|c|c|c|c|c|c|c|c|c|c|}
\hline \multicolumn{12}{|c|}{$\begin{array}{l}\text { TABLE I } \\
\text { nd clinical characteristics of patients operated fo }\end{array}$} \\
\hline & \multicolumn{5}{|c|}{ Plate } & \multicolumn{5}{|c|}{ Cannulated lag screw } & \multirow[b]{2}{*}{$p^{*}$} \\
\hline & $\mathrm{n}$ & $\%$ & Mean \pm SD & Median & Min-Max & $\mathrm{n}$ & $\%$ & Mean $\pm S D$ & Median & Min-Max & \\
\hline Age (year) & & & $42.1 \pm 13.8$ & 41.5 & $20-76$ & & & $45.5 \pm 12.2$ & 42.5 & $25-73$ & 0.41 \\
\hline Gender & & & & & & & & & & & 0.62 \\
\hline Male & 24 & 64.9 & & & & 17 & 70.8 & & & & \\
\hline Female & 13 & 35.1 & & & & 7 & 29.2 & & & & \\
\hline Body mass index $\left(\mathrm{kg} / \mathrm{m}^{2}\right)$ & & & $26.7 \pm 1.5$ & & & & & $27.4 \pm 1.6$ & & & 0.55 \\
\hline Duration of surgery (min) & & & $133.1 \pm 56.2$ & & & & & $99.3 \pm 55.3$ & & & $<0.001$ \\
\hline Hospital stay (day) & & & $4.1 \pm 1.9$ & & & & & $3.0 \pm 1.5$ & & & 0.03 \\
\hline Autograft need (n) & & & & & $25-67.5$ & & & & & $15-63$ & 0.42 \\
\hline Cost (USD) ${ }^{* *}$ & & & $696.7 \pm 242$ & & & & & $211.6 \pm 116$ & & & $<0.001$ \\
\hline Ahlback classification ${ }^{* * *}$ & & & & & & & & & & & 0.8 \\
\hline \multicolumn{12}{|l|}{ Preoperative } \\
\hline Grade 0 & & & & & $30-81$ & & & & & $20-83.3$ & \\
\hline Grade 1 & & & & & $7-19$ & & & & & $4-16.7$ & \\
\hline \multicolumn{12}{|l|}{ Postoperative } \\
\hline Grade 0 & & & & & $25-67.5$ & & & & & $15-62.5$ & \\
\hline Grade 1 & & & & & $8-21.6$ & & & & & $5-20.8$ & \\
\hline Grade 2 & & & & & $4-10.8$ & & & & & $4-16.6$ & \\
\hline Instability findings mediolateral & & & & & & & & & & & 0.39 \\
\hline No & & & & & $19-51.3$ & & & & & $15-62.5$ & \\
\hline Yes & & & & & $18-48.7$ & & & & & $9-37.5$ & \\
\hline Instability anteroposterior & & & & & & & & & & & 0.94 \\
\hline No & & & & & $25-67.5$ & & & & & $16-66.6$ & \\
\hline Yes & & & & & $12-32.5$ & & & & & $8-33.3$ & \\
\hline Single-leg hop test & & & & & & & & & & & 0.55 \\
\hline No & & & & & $7-18.9$ & & & & & $5-20.9$ & \\
\hline Yes & & & & & $30-81.1$ & & & & & $19-79.1$ & \\
\hline Final knee flexion extension ROM & & & $119.7 \pm 9.4$ & & & & & $121.6 \pm 9.7$ & & & 0.4 \\
\hline
\end{tabular}




\begin{tabular}{|c|c|c|c|c|}
\hline \multicolumn{5}{|c|}{$\begin{array}{l}\text { TABLE II } \\
\text { Functional scores and range of motion values }\end{array}$} \\
\hline & Groups & Mean $\pm S D$ & $95 \% \mathrm{Cl}$ & $p$ \\
\hline \multicolumn{5}{|l|}{ Short form 36} \\
\hline \multirow[t]{2}{*}{ Physical functional } & Plate & $75 \pm 20$ & $68-82$ & \multirow{2}{*}{0.53} \\
\hline & Screw & $78 \pm 25$ & $69-87$ & \\
\hline \multirow[t]{2}{*}{ Physical role } & Plate & $82 \pm 24$ & $73-90$ & \multirow{2}{*}{0.38} \\
\hline & Screw & $87 \pm 21$ & $78-96$ & \\
\hline \multirow[t]{2}{*}{ Pain } & Plate & $77 \pm 23$ & $69-84$ & \multirow{2}{*}{0.28} \\
\hline & Screw & $83 \pm 20$ & $75-92$ & \\
\hline \multirow[t]{2}{*}{ General health } & Plate & $78 \pm 18$ & $72-84$ & \multirow{2}{*}{0.78} \\
\hline & Screw & $79 \pm 18$ & $72-87$ & \\
\hline \multirow[t]{2}{*}{ Vitality } & Plate & $78 \pm 15$ & $72-83$ & \multirow{2}{*}{0.51} \\
\hline & Screw & $75 \pm 16$ & $67-82$ & \\
\hline \multirow[t]{2}{*}{ Social function } & Plate & $80 \pm 24$ & $71-89$ & \multirow{2}{*}{0.48} \\
\hline & Screw & $84 \pm 17$ & $77-92$ & \\
\hline \multirow[t]{2}{*}{ Emotional role } & Plate & $89 \pm 19$ & $81-96$ & \multirow{2}{*}{0.87} \\
\hline & Screw & $90 \pm 21$ & $80-99$ & \\
\hline \multirow[t]{2}{*}{ Mental health } & Plate & $78 \pm 17$ & $72-84$ & \multirow{2}{*}{0.91} \\
\hline & Screw & $78 \pm 21$ & $69-87$ & \\
\hline \multicolumn{5}{|l|}{ KSS } \\
\hline \multirow[t]{2}{*}{ KSS knee score } & Plate & $81 \pm 11$ & $77-85$ & \multirow{2}{*}{0.21} \\
\hline & Screw & $85 \pm 12$ & $80-90$ & \\
\hline \multirow[t]{2}{*}{ KSS functional score } & Plate & $81 \pm 14$ & $76-86$ & \multirow{2}{*}{0.19} \\
\hline & Screw & $86 \pm 12$ & $80-91$ & \\
\hline \multicolumn{5}{|l|}{ HSS } \\
\hline \multirow[t]{2}{*}{ Hospital for SSS } & Plate & $83 \pm 12$ & $79-87$ & \multirow{2}{*}{0.15} \\
\hline & Screw & $87 \pm 9$ & $83-91$ & \\
\hline
\end{tabular}

difference between the two groups regarding clinical and functional scores such as SF-36, KSS, and HSS at last follow-up (Table II).

Eleven patients (five patients in group 1 and six in patients in group 2; $\mathrm{p}=0.64$ ) had lateral meniscal tear or meniscocapsular injury. They were all repaired intraoperatively. Three patients in group 2 had superficial wound infection. They were treated with wound debridement and oral antibiotherapy. Also, eight patients (21.6\%) in group 2 had implant irritation. Their implants were removed at postoperative one year.

\section{DISCUSSION}

The most important finding of our study was that there was no statistically significant difference in the clinical and radiological outcomes between the lag screw group and the anatomic plate group. ${ }^{[10]}$ In addition, hospitalization and operation durations were shorter, the cost of materials used during surgery was lower, and treatment could be performed less invasively in the lag screw group.

In their cadaveric study, Boisrenoult et al. ${ }^{[5]}$ reported no statistical difference between lateral pre-bent plates and double lag screws regarding biomechanical stability. This finding is consistent with our study. Van Dreumel et al. ${ }^{[11]}$ evaluated the results of surgical treatment of tibial plateau fractures; lag screw fixation was applied in the treatment of Schatzker type II fractures. However, it was emphasized that these patients might have had good bone quality and simple fractures. Most of the 
patients in our study were male $(67 \%)$ and the mean age was relatively younger. Thus, bone quality was also considered to be good in our patients.

Sament et al. ${ }^{[12]}$ treated tibial plateau fractures with percutaneous lag screw technique and showed good results at a mean follow-up of three years. In this study, percutaneous lag screw fixation was demonstrated to reduce the length of hospital stay and costs and enabled early mobilization; however, possible intraarticular pathologies were not evaluated and no intervention was performed for these during surgery. In our study, meniscal tears detected by arthrotomy in 11 patients were treated simultaneously and autograft was applied for some fractures. In addition, the joint line was visible directly and anatomic reduction was confirmed. Therefore, we recommend percutaneous fixation in fractures with lesser depression and low-energy injuries where the risk of concomitant soft tissue injury is lower.

In a study of Siegler et al., ${ }^{[13]}$ Schatzker type II fractures were treated with arthroscopy-assisted lag screw fixation. Osteoarthritis was seen in $46 \%$ of the patients in the long-term follow-up period and $80 \%$ of them were determined to be stage 1 according to the Ahlback classification. In this study, age was found to be a risk factor for osteoarthritis development and it had no negative impact on clinical outcomes other than returning to sports. In our study, the average rate of development of osteoarthritis was approximately $35 \%$ at a mean follow-up of 34 months, and most of them $(60 \%)$ were at stage 1 . We did not use arthroscopy and our results were slightly better, while our follow-up time was shorter. Hung et al. ${ }^{[14]}$ found the results of arthroscopy-assisted surgery to be successful and patients who had intraarticular pathology could be intervened simultaneously. In our study, intraarticular pathologies were controlled by partial arthrotomy and successful results were obtained without the need for arthroscopy.

Moreover, Russell et al. ${ }^{[4]}$ compared the results of autograft with calcium phosphate cement in the treatment of tibial plateau fractures and calcium phosphate was found to be more successful. Authors did not mention how much calcium phosphate cement increased the cost while we could get successful results in our study by using autograft. Berkes et al. ${ }^{[15]}$ followed Schatzker type II fractures for two years and compared using allograft with calcium phosphate cement, determining similar results within each group. Compared to our study, higher-cost implants were used and similar clinical results were found. Ollivier et al. ${ }^{[16]}$ corrected depression by using balloon tibioplasty in lateral plateau fractures present with depression and applied fixation with lag screws; the results were also successful. We do not need a procedure that increases the cost of treatment considerably and can provide autografts if the similar functional outcomes are sought.

Surgical treatment provides mechanical joint stability and starting immediate ROM while knee joint function is regained. The main purpose is to deliver long-term survival by preventing a possible traumatic, secondary osteoarthritis. By anatomic reduction of the joint cartilage and providing proper mechanical axis, secondary osteoarthritis may be prevented. There was no statistically significant difference in post-traumatic arthritis between the two groups. This shows us that the type of fixation does not have any effect on arthritis in short- and medium-terms.

The retrospective nature, relatively small sample size, and lack of long-term clinical and radiological outcomes were the limitations of our study.

In conclusion, surgical treatment of Schatzker type II tibial plateau fractures with lag screws provide less invasive, cheaper, and faster surgical opportunity as compared with lateral locking plate fixation in patients with good bone quality. Furthermore, internal fixation with lag screws has similar clinical and radiological outcomes compared to lateral locking plate fixation.

\section{Declaration of conflicting interests}

The authors declared no conflicts of interest with respect to the authorship and/or publication of this article.

\section{Funding}

The authors received no financial support for the research and/or authorship of this article.

\section{REFERENCES}

1. Zeltser DW, Leopold SS. Classifications in brief: Schatzker classification of tibial plateau fractures. Clin Orthop Relat Res 2013;471:371-4.

2. Honkonen SE. Indications for surgical treatment of tibial condyle fractures. Clin Orthop Relat Res 1994;302:199-205.

3. Rademakers MV, Kerkhoffs GM, Sierevelt IN, Raaymakers EL, Marti RK. Operative treatment of 109 tibial plateau fractures: five- to 27-year follow-up results. J Orthop Trauma 2007;21:5-10.

4. Russell TA, Leighton RK; Alpha-BSM Tibial Plateau Fracture Study Group. Comparison of autogenous bone graft and endothermic calcium phosphate cement for defect augmentation in tibial plateau fractures. A multicenter, prospective, randomized study. J Bone Joint Surg [Am] 2008;90:2057-61.

5. Boisrenoult P, Bricteux S, Beaufils P, Hardy P. Screws versus screw-plate fixation of type 2 Schatzker fractures of the lateral tibial plateau. Cadaver biomechanical study. 
Arthroscopy French Society. Rev Chir Orthop Reparatrice Appar Mot 2000;86:707-11.

6. Kohn MD, Sassoon AA, Fernando ND. Classifications in Brief: Kellgren-Lawrence Classification of Osteoarthritis. Clin Orthop Relat Res 2016;474:1886-93.

7. Ahlbäck S, Rydberg J. X-ray classification and examination technics in gonarthrosis. Lakartidningen 1980;77:2091-3.

8. Insall JN, Dorr LD, Scott RD, Scott WN. Rationale of the Knee Society clinical rating system. Clin Orthop Relat Res 1989;248:13-4.

9. Bach $C M$, Nogler $M$, Steingruber IE, Ogon $M$, Wimmer $C$, Göbel G, et al. Scoring systems in total knee arthroplasty. Clin Orthop Relat Res 2002;399:184-96.

10. Atik OS. Is there something new and interesting in my article? Eklem Hastalik Cerrahisi 2019;30:69.

11. van Dreumel RL, van Wunnik BP, Janssen L, Simons PC, Janzing HM. Mid- to long-term functional outcome after open reduction and internal fixation of tibial plateau fractures. Injury 2015;46:1608-12.
12. Sament R, Mayanger JC, Tripathy SK, Sen RK. Closed reduction and percutaneous screw fixation for tibial plateau fractures. J Orthop Surg (Hong Kong) 2012;20:3741.

13. Siegler J, Galissier B, Marcheix PS, Charissoux JL, Mabit C, Arnaud JP. Percutaneous fixation of tibial plateau fractures under arthroscopy: a medium term perspective. Orthop Traumatol Surg Res 2011;97:44-50.

14. Hung SS, Chao EK, Chan YS, Yuan LJ, Chung PC, Chen CY, et al. Arthroscopically assisted osteosynthesis for tibial plateau fractures. J Trauma 2003;54:356-63.

15. Berkes MB, Little MT, Schottel PC, Pardee NC, Zuiderbaan A, Lazaro LE, et al. Outcomes of Schatzker II tibial plateau fracture open reduction internal fixation using structural bone allograft. J Orthop Trauma 2014;28:97-102.

16. Ollivier M, Turati M, Munier M, Lunebourg A, Argenson JN, Parratte S. Balloon tibioplasty for reduction of depressed tibial plateau fractures: Preliminary radiographic and clinical results. Int Orthop 2016;40:1961-6. 